\title{
A SIMULATION FRAMEWORK FOR CONTROLLED CRITICAL INFRASTRUCTURES SUBJECT TO NATURAL DISASTERS
}

\section{Amir Mohammed ${ }^{*}$, Craig J. Ramlal ${ }^{2}$, Arvind Singh ${ }^{3}$, Sean Rocke ${ }^{4}$ and Daniel Goitia $^{5}$}

\author{
Faculty of Engineering, The University of the West Indies, Trinidad \\ ${ }^{1}$ Email: amirmohammed45@gmail.com*(Corresponding author) \\ ${ }^{2}$ Email: Craig.Ramlal@ sta.uwi.edu \\ ${ }^{3}$ Email: Arvind.Singh@sta.uwi.edu \\ ${ }^{4}$ Email: Sean.Rocke@sta.uwi.edu \\ ${ }^{5}$ Email: Daniel.Goitia@sta.uwi.edu
}

\begin{abstract}
Natural disasters are inherently unpredictable and can cause major damage to critical infrastructures in cities and loss of life. In this study, a simulation and control framework was developed for evaluating response decisions for natural disaster scenarios with the objective of minimizing the casualties generated from within the simulation. The package was developed in MATLAB Simulink using the infrastructure interdependencies simulator (I2Sim) with a test system of six small residences, one large residence, two health centres, one large hospital, three water pumps of varying capacities and one energy production cell. The research focused on the development of heuristic controllers to evaluate the best possible outcome given the disaster scenario simulated to affect critical infrastructure. Response decisions were generated for 625 unique scenarios, this information once grouped, can be used to inform response policies after natural disasters.
\end{abstract}

Keywords: Disaster Management, Heuristic Control, Natural Disasters, Response Policy, I2Sim.

https://doi.org/10.47412/FZEP7016

\section{Introduction}

The wake of natural disasters have revealed the importance of properly coordinated emergency measures to aid in the reduction of casualties. Resource management was highlighted as a crucial element in the event of natural or man-made disasters which would help to maximize the number of saved lives without wastage of economic resources. Restoring electricity is highly prioritized since this increases the productivity and effectiveness of critical infrastructure such as hospitals and water distribution services. The interdependency between such infrastructures have been considered in light of service restoration [1]. Studies involving the use of either genetic or heuristic algorithms for the problem of resource allocation during a disaster event with a focus on objective based optimization were investigated and presented in [2], [3], [13], [14] and [16]. Hence resource allocation proves to be a critical challenge as it relates to the distribution of resources in a situation where resources are limited and the decisions made can affect the loss of life.

Disaster management policies have been introduced in Pakistan's 2010 disaster management act as a critical analysis; this case highlights the importance for the development of policies and practices as it relates to disaster management [4]. Simulation of real-life scenarios, aids in disaster management as it provides researchers a better understanding of how real-life systems can behave and what actions should be taken to 
reduce its effects. However, such simulations require a lot of accurate real-life data for model building. The use of accurate data in the simulation of real systems leads to useful insights into operational limitations. Such limitations can be gathered from the simulation of the failure of a steam plant to see the effects which would take place in [5]. An intelligent agent based on reinforcement learning was proposed, this approach focused on maximizing of the number of patients being discharged from emergency units by taking the necessary actions needed to reduce deaths [6]. Similar research has made use of neural networks and loss functions which performs multitask learning processes on models while improving the learning speed of optimization algorithms [7]. A utility driven post disaster emergency resource allocation system using delay tolerant networks has been proposed which minimizes resource deficit and resource deployment time [15]. The focus of such simulations allowed emergency responders to take the necessary actions based on particular disaster scenarios and hence introduces a policy framework which should exist for disaster events. Policy measures exist for various countries such as Uganda with assessments of the extent to which landslides affect individuals [8]. More recent work focused on the presence of disaster debris management plans [9] and geo simulations in Pakistan with near real time policy responses using data collected after an earthquake disaster [10]. Disaster prevention and control management attempts to handle disasters as they are experienced by making use of policy frameworks and any preventative measures developed from time to time [11]. The contribution of this paper is the development of a simulation framework for policy evaluation of critical infrastructure subject to natural disasters. The research showcases the integration of heuristic controllers which can be used to generate the best disaster policies for given disaster scenarios, on critical infrastructure within the model. The paper is structured as follows, section 2 gives a breakdown of the I2Sim model, section 3 highlights the testing procedures developed for each critical infrastructure, section 4 presents the results for each test conducted and section 5 contains the discussion and generation of the disaster policies

\section{Overview of I2Sim Model}

The infrastructure interdependency simulator (I2Sim) [12] was used in this study for implementing disaster scenarios. Each cell within I2Sim consists of Physical Modes (PMs) which model the input output relationships for different operational scenarios. The breakdown of these PMs within the I2Sim module was represented in a Human Resource Table (HRT) for each cell. The HRT was used to represent the operational behavior of a cell either by reduction of a resource supplied to it or damages caused to the cell from a disaster. The developed i2sim model consisted of several critical infrastructure for a disaster event. The model contained one large residence, six small residences, two small health centers, one large hospital, three water pumps and one energy production cell. The energy production cell was one of the two primary inputs fed into all other production cells in the model. The interdependency structure can be seen in Figure 21. The design of the model is intended to replicate a small state and was implemented using I2Sim toolbox and MATLAB Simulink R2018b.

\subsection{Energy Production Cell}

The energy production cell was used to provide power to every element within the interdependency model. The energy production cell at full functionality (PM 1) supplied power to 7 loads shown in Figure 21. A load can be thought as a cell or group of cells which consume power from the energy production cell. This cell contains 5 PMs in total and its behavior is shown in Table 16. 
Table 16: PM behaviour of Energy Production Cell

\begin{tabular}{|c|c|c|}
\hline $\begin{array}{l}\text { Energy Production Cell } \\
\text { Physical Mode (PM) }\end{array}$ & $\begin{array}{l}\text { Number of Loads Energy being } \\
\text { Supplied to }\end{array}$ & $\begin{array}{l}\text { Number of Loads Energy } \\
\text { Not being Supplied To }\end{array}$ \\
\hline 1 & All Loads Turned on & 0 \\
\hline 2 & 6 & 1 \\
\hline 3 & 6 & 3 \\
\hline 4 & 4 & 7 \\
\hline 5 & 0 & Load D) \\
\hline
\end{tabular}

\subsection{Residence Production Cell}

The residence production cell was used to represent the population of persons involved in the disaster scenario. The entire population consisted of one large residence with a population of 20000 and six small residences with a population of 5000 persons per residence, giving a total of 50000 individuals for this study. Table 17 shows the input output relationship for the residences.

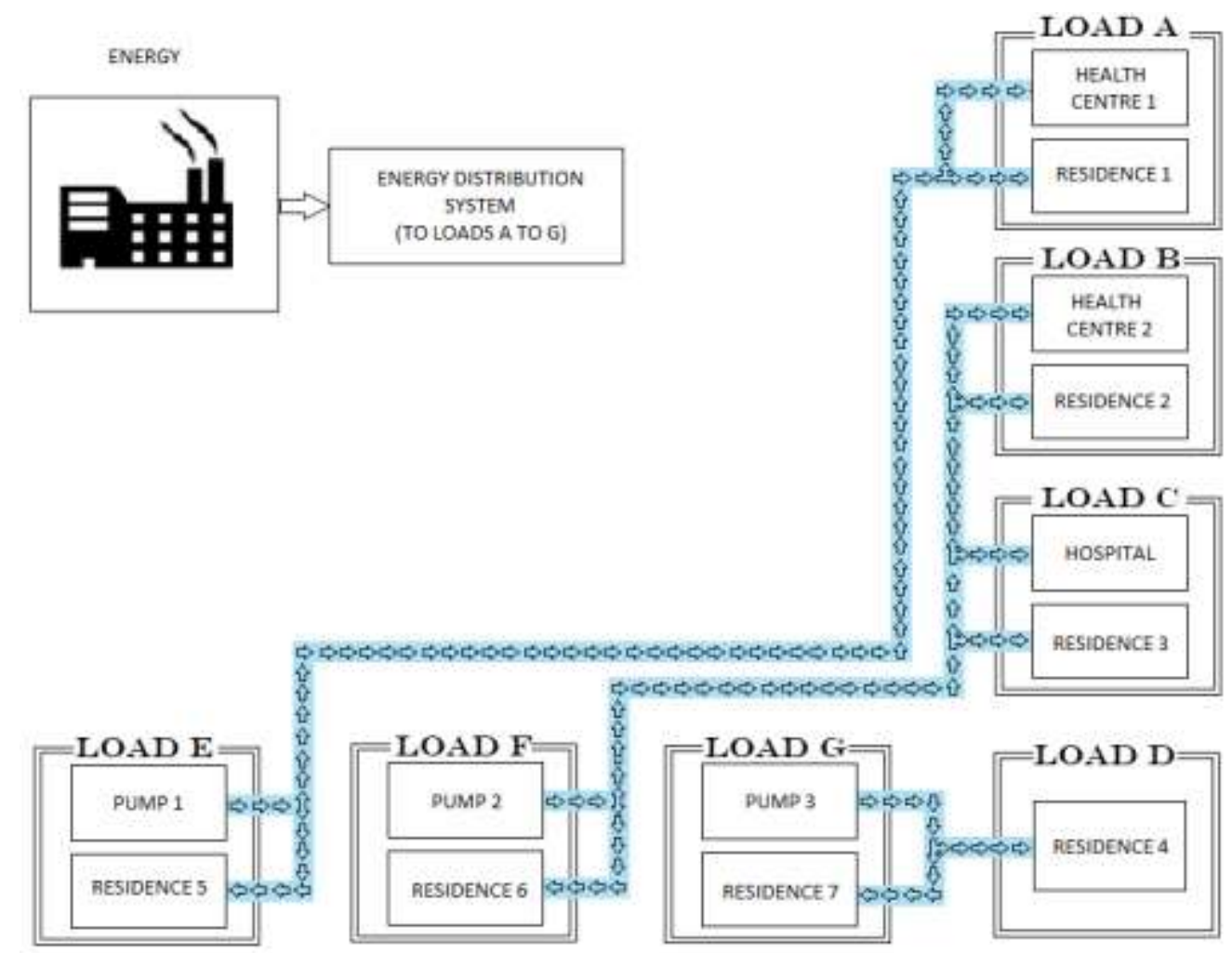

Figure 21: Overview of System 
Table 17: HRT for small and large residences

\begin{tabular}{|l|l|l|l|l|l|l|l|l|l|l|}
\hline \multicolumn{5}{|c|}{ HRT for small residences } & \multicolumn{7}{c|}{ HRT for large residences } \\
\hline Power/MW & 1 & 1 & 1 & 0 & 0 & 1 & 1 & 1 & 0 & 0 \\
\hline Water/L & 62500 & 60000 & 50000 & 25000 & 0 & 250000 & 240000 & 200000 & 100000 & 0 \\
\hline Sickly Generated & 0 & 25 & 50 & 75 & 100 & 0 & 100 & 200 & 300 & 400 \\
\hline
\end{tabular}

\subsection{Water Production Cell}

The water production cell was used to generate water resources in the i2sim model. This was the second primary input used by various cells in the model. The water production cell provided water to all its dependent cells at full capacity (PM 1). This cell was represented by three pumps and the cells dependent on each pump was shown in Figure 21. Table 18 shows the breakdown of the output rate (litres/cycle) for the pumps and its respective physical modes. This output of the water production cell was sent to a distribution system which allocates resources to each of their dependents. It should also be noted that each pump forms part of a load in the model and is only functional when the load is "ON". See Figure 21.

Table 18: The Output (litres) of each Pump for the possible PMs

\begin{tabular}{|c|c|c|c|c|c|}
\hline \multirow{2}{*}{ Pump } & \multicolumn{5}{|c|}{ Physical Mode (PM) } \\
\cline { 2 - 6 } & $\mathbf{1}$ & $\mathbf{2}$ & $\mathbf{3}$ & $\mathbf{4}$ & $\mathbf{5}$ \\
\hline $\mathbf{1}$ & 250000 & 187500 & 125000 & 62500 & 0 \\
\hline $\mathbf{2}$ & 250000 & 187500 & 125000 & 62500 & 0 \\
\hline $\mathbf{3}$ & 500000 & 375500 & 250000 & 125000 & 0 \\
\hline
\end{tabular}

\subsection{Hospital and Health Centre (HC) Production cells}

The hospital and health center production cells are responsible for the treatment of casualties during the disaster scenario. Residences R1, R5, R6 and R7 are assigned to HC1 and R2, R3 and R4 are assigned to HC2 and Hospital. Its functionality (Treatment Rate) was dependent on both the energy and water resources supplied to these production cells. Table 19: The HRT for the Hospital below show the HRTs for these cells.

Table 19: The HRT for the Hospital and Health Centres

\begin{tabular}{|c|c|c|c|c|c|c|c|c|c|c|}
\hline \multicolumn{4}{|c|}{ HRT for the Hospital } & \multicolumn{5}{c|}{ HRT for the Health Centres } \\
\hline Power & 1 & 1 & 1 & 0 & 0 & 1 & 1 & 1 & 0 & 0 \\
\hline Water/L & 5000 & 4250 & 3500 & 1000 & 0 & 1500 & 1250 & 1000 & 500 & 0 \\
\hline Treatment Rate & 200 & 175 & 50 & 25 & 0 & 50 & 40 & 20 & 10 & 0 \\
\hline
\end{tabular}

\subsection{Death}

In the model the death value was recorded as an iterative collection of failed treatments. The death parameter is an important aspect as it relates to disaster scenarios. Death is one of the major aspects disaster 
emergency and preparedness attempt to mitigate. Therefore, death can be used as the metric to determine the best possible outcome for a given disaster scenario.

\section{Testing Procedures and Control Strategies}

The testing procedure focused on varying the main inputs to the system, while generating numerous scenarios for different critical infrastructure conditions and its dependent cells. Two general test cases for the energy and water inputs were considered. The development of the test scenarios formed a systematic approach to evaluate how the main inputs to the system would affect the system's overall performance when damaged and the death values being generated for each given scenario.

\subsection{Energy Production Cell Test Cases}

\subsubsection{Heuristic Controller for Energy Production Cell}

Referring to Table 16, the test cases for PMs 1, 3 and 5 can be seen as single test cases. However, for PMs 2 and 4 all possible cases were included. Thus, a greedy (brute force approach) algorithm was used to examine each disaster scenario.

In Eq. 1, $n$ is the total number of loads and $r$ is the number of loads 'on'. The expression gives the number of unique combinations required to test in order to evaluate the entire effect on the system.

$$
\boldsymbol{T}=\frac{\boldsymbol{n} !}{\boldsymbol{r} !(\boldsymbol{n}-\boldsymbol{r}) !}
$$

The aim of the heuristic controller was to determine the distribution which best reduces the number of deaths experienced during a disaster test scenario. This is executed through comparison of the results for each scenario and choosing the most optimal distribution. The flowchart of this controller is shown in Figure 22.

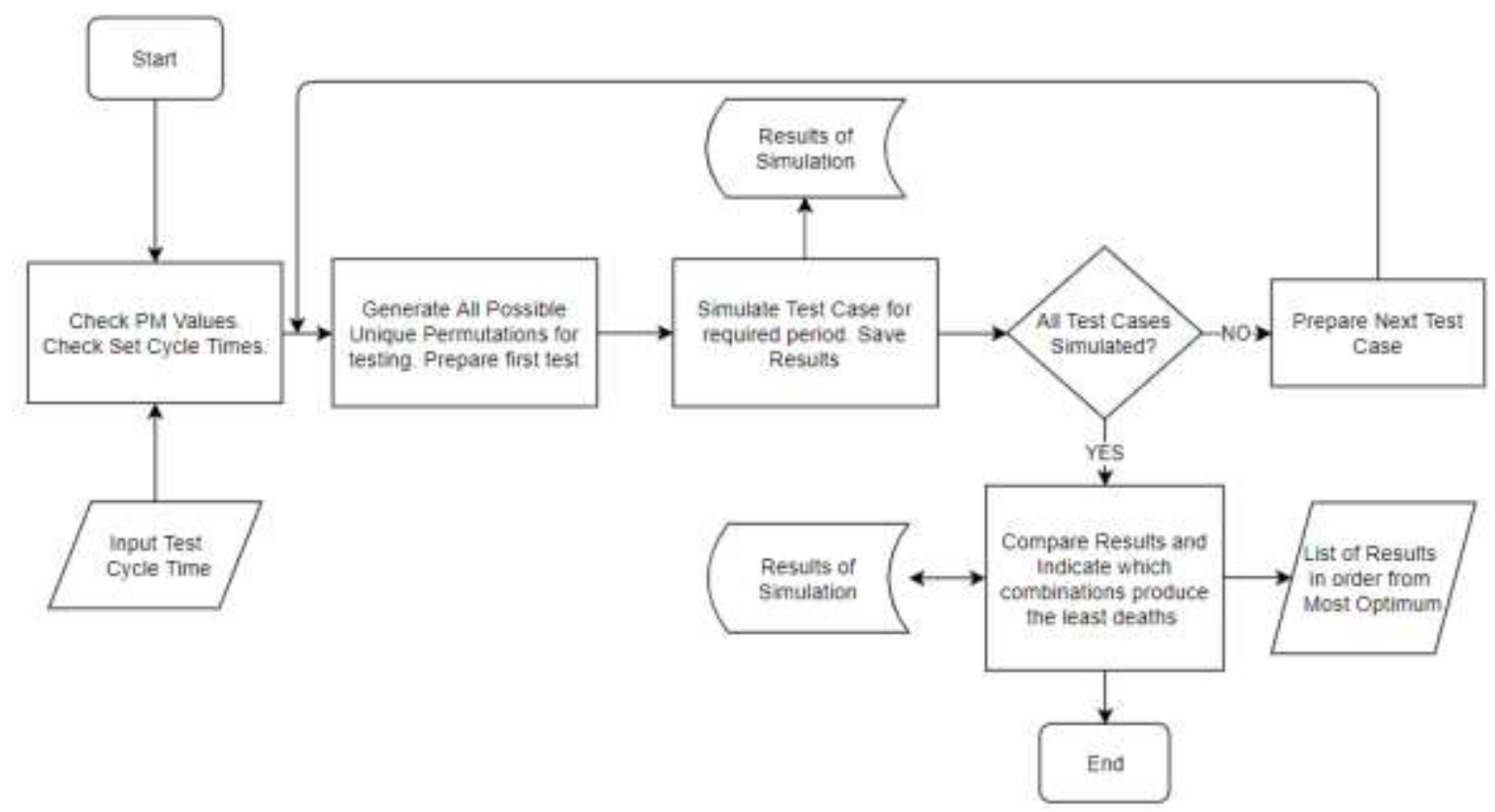

Figure 22: Heuristic Controller for Energy Production Cell 


\subsubsection{Rotation of Loads (Rotating Black out) and No Rotation of Loads Simulated}

The rotating black out was a specific situation in which loads were turned on and off for a specific period (of time). For each physical mode the number of combinations which existed was different as mentioned previously. At each simulated iteration, a unique combination of PMs were executed for a specific period until every unique combination of PMs were simulated with the controller reporting the best combination of load rotations (loads which should be left on).

\subsection{Water Production Cell Test Cases}

Recall the water production cell was represented by three pumps at various locations within the model (See Figure 21) where the behavior of the pumps can be seen in Table 18. A heuristic distributor was developed to deliver the water resources to its dependents, while maintaining the most efficient distribution ratio. The distributor's aim was to operate in a manner that provided the best ratio between the sickly generated from residences and treatment rate at Health Care Cells (Health Centres) with emphasis on reducing deaths.

\subsubsection{Testing Procedure for Water Production Cell}

Similar to the test procedures used for the Energy Production Cell, all possible unique PM combinations were tested for each cell. However, these cases required the use of unique test combinations for the three (3) pumps. During this procedure the test cases were broken up into three parts: (1) One pump damaged all combinations which involved only one pump being damaged were tested with two pumps maintained at PM 1. (2) Two pumps damaged - all combinations which involved only one pump undamaged, this pump was maintained at PM 1 while varying the PM values of the other two pumps. (3) All pumps damaged - all possible unique combinations of the PM which simulated all 3 pumps experiencing some level of damage simultaneously.

\subsection{Movement of People (MOP) and Truck Borne Supply (TBS)}

These two methods can be thought as preventative actions (PA) that can be performed in a given situation to reduce the number of deaths due to lack of treatment or resources at a particular location. The movement of people was a relief method in which the sickly from an overcrowded health unit was moved to another health unit that was not overcrowded. The truck borne supply strategy was a relief method in which water resources were delivered to cells anywhere in the model as a truck borne supply. The relief methods can be used within the energy and water test cases to aid in reducing the number of deaths generated.

\section{Results}

\subsection{Energy Production Cell}

Referring to Table $\mathbf{1 6}$ for the behaviour of the Energy Production Cell. PM 1 is normal operation while PM 5 can be induced to show maximum deaths.

\subsubsection{Physical Mode 2}

Table 20: Rotation of Loads Results for PM2

\begin{tabular}{|l|l|l|l|l|l|l|l|}
\hline \multirow{2}{*}{$\begin{array}{l}\text { Tested } \\
\text { Combinations }\end{array}$} & \multicolumn{7}{|c|}{ Active Loads } \\
\cline { 2 - 8 } & $\begin{array}{l}\text { A B C D } \\
\text { E F }\end{array}$ & $\begin{array}{l}\text { A B C D } \\
\text { E G }\end{array}$ & $\begin{array}{l}\text { A B C D } \\
\text { F G }\end{array}$ & $\begin{array}{l}\text { A B C E } \\
\text { F G }\end{array}$ & $\begin{array}{l}\text { A B D E F } \\
\text { G }\end{array}$ & $\begin{array}{l}\text { A C D E F } \\
\text { G }\end{array}$ & $\begin{array}{l}\text { B C D E } \\
\text { F G }\end{array}$ \\
\hline $\begin{array}{l}\text { Water } \\
\text { Resources/L }\end{array}$ & 320500 & 439000 & 500000 & 481500 & 590000 & 591750 & 588000 \\
\hline $\begin{array}{l}\text { Death } \\
\text { Recorded }\end{array}$ & 200 & 250 & 200 & 50 & 0 & 0 & 65 \\
\hline
\end{tabular}




\begin{tabular}{|l|l|l|l|l|l|l|l|}
\hline $\begin{array}{l}\text { MOP } \\
\text { employed }\end{array}$ & $\begin{array}{l}\text { No } \\
\text { change }\end{array}$ & $\begin{array}{l}\text { No } \\
\text { Change }\end{array}$ & 0 & 0 & $\begin{array}{l}\text { Not } \\
\text { needed }\end{array}$ & $\begin{array}{l}\text { Not } \\
\text { Needed }\end{array}$ & 0 \\
\hline
\end{tabular}

\subsubsection{Physical Mode 3}

At PM 3, load D cannot be turned on due to the nature of the model. The death recorded was 50 with $481500 \mathrm{~L}$ of water usage with a tested load combination of ABCEFG.

\subsubsection{Physical Mode 4}

Table 21: Rotation of Load Results for PM 4 below shows extracted results for PM 4.

Table 21: Rotation of Load Results for PM 4

\begin{tabular}{|l|l|l|l|l|l|}
\hline \multirow{2}{*}{$\begin{array}{l}\text { Tested } \\
\text { Combinations }\end{array}$} & \multicolumn{5}{|c|}{ Active Loads } \\
\cline { 2 - 6 } & A B E F & A B E G & A B F G & A E F G & B E FG \\
\hline Death Recorded & 450 & 500 & 500 & 415 & 365 \\
\hline MOP & 325 & 425 & 190 & 365 & 190 \\
\hline
\end{tabular}

\subsection{Water Production Cells}

In this section the water distribution was tested, each pump was damaged in a systematic manner to observe the model behavior. The results show the cumulative results for sickly persons generated from all residences, the treatment rate (TR) over all Health Care Cells (Health Centres) and the deaths incurred when the pumps were subjected to damages. Refer to Section 3.2.1 for testing procedure outline.

\subsubsection{One Pump Damaged}

Table 22 shows the comparison of test results for only one pump being damaged.

Table 22: Comparison of Results for Only One Pump Damaged Cases

\begin{tabular}{|c|c|c|c|c|c|c|c|c|c|}
\hline $\begin{array}{c}\text { Physical } \\
\text { Mode of } \\
\text { Damaged } \\
\text { Pump }\end{array}$ & \multicolumn{2}{|l|}{ Pump One Damaged } & \multicolumn{2}{|c|}{ Pump Two Damaged } & \multicolumn{3}{|c|}{ Pump Three Damaged } \\
\cline { 2 - 10 } & Sickly & $\begin{array}{c}\text { Total } \\
\text { Death }\end{array}$ & MOP & Sickly & TR & $\begin{array}{c}\text { Total } \\
\text { Death }\end{array}$ & Sickly & $\begin{array}{c}\text { Total } \\
\text { Death }\end{array}$ & MOP \\
\hline $\mathbf{1}$ & 0 & 0 & 0 & 0 & 0 & 0 & 0 & 0 & 0 \\
\hline $\mathbf{2}$ & 0 & 0 & 0 & 50 & 50 & 0 & 0 & 0 & 0 \\
\hline $\mathbf{3}$ & 25 & 0 & 0 & 150 & 150 & 0 & 100 & 50 & 0 \\
\hline $\mathbf{4}$ & 125 & 75 & 0 & 250 & 250 & 0 & 375 & 75 & 75 \\
\hline $\mathbf{5}$ & 200 & 200 & 0 & 300 & 50 & 250 & 500 & 200 & 200 \\
\hline
\end{tabular}

\subsubsection{Two Pumps Damaged}

The results of this simulation showed the comparison of the cumulative results for sickly people generated from all residences, the Treatment Rate (TR) over all Health Care Cells (Health Centres) and the Deaths incurred while only one pump was undamaged. Therefore, the tested scenarios were conducted as follows; Pump 1 undamaged while Pump 2 and Pump 3 were damaged. Pump 2 undamaged while Pump 1 and Pump 3 were damaged and lastly Pump 3 undamaged while Pump 1 and Pump 2 were damaged. Table 23: Comparison of results for Only 1 Pump Undamaged Cases presents when Pump 1 was undamaged and Pump 2 and Pump 3 damaged. 
Table 23: Comparison of results for Only 1 Pump Undamaged Cases

\begin{tabular}{|c|c|c|c|c|c|c|}
\hline Physical Mode & Physical Mode & \multicolumn{2}{|c|}{ Pump 1 Undamaged } & \multicolumn{2}{c|}{ Simulated with PA } \\
\hline Pump 2 & Pump 3 & Sickly & TR & $\begin{array}{c}\text { Total } \\
\text { Death }\end{array}$ & PA & $\begin{array}{c}\text { Death } \\
\text { Recorded } \\
\text { with PA }\end{array}$ \\
\hline 1 & 1 & 0 & 0 & 0 & - & - \\
\hline 1 & 2 & 0 & 0 & & - & - \\
\hline 2 & 1 & 50 & 50 & 0 & - & - \\
\hline 2 & 2 & 50 & 50 & 0 & - & - \\
\hline 1 & 4 & 375 & 300 & 75 & TBS & 0 \\
\hline 2 & 3 & 150 & 100 & 50 & MOP & 0 \\
\hline 5 & 3 & 400 & 50 & 350 & TBS & 0 \\
\hline 5 & 4 & 675 & 50 & 625 & TBS & 225 \\
\hline
\end{tabular}

\section{Discussion}

\subsection{Energy Production Policies}

The energy distributor was responsible for sending power to various loads within the model as needed. Given the output power available from the energy production cell, both blocks worked together to facilitate the execution of all tested scenarios for data collection. Table $\mathbf{2 0}$ showed the effect of taking off each load while the rest of the system operates normally. It was evident that loads E, F and G had the most severe impact on the overall system. This was as a result of the system's dependency on the water pumps and this led to a cascaded failure of dependent cells within the loads when pumps were turned off. The other results showed the effects of turning off loads $\mathrm{C}$ and $\mathrm{B}$ to be minimal on the system. This was due to two factors, (1) When only one cell was operating at a deficient level, this results in relatively less sickly individuals and the sickly were able to be treated by the medical facilities; (2) Even though one load was turned off, due to the nature of the HRT for medical and residence cells, the limited water resource would have the greatest impact on these cells performance. Given a situation where a load was turned off and Health Care (Health Centre) production cells still has the ability to obtain water resources, these cells would be operating in a restricted state and would not be completely turn off. Loads E, D and A death values were reduced to zero when the MOP method was used, allowing other medical cells to assist when the default assignment was unable to handle the situation.

At this physical mode since three loads were unable to be turned on, it contributed to a large buildup of sickly being sent to the medical facilities resulting in many deaths. The combination of loads that generated the lowest number of deaths when turned on were A E F G and B E F G. These two load combinations contained the loads E F G which were critical to ensure water was supplied to the system.

From the results of Section 4.1, the prioritization of loads with respect to power distribution can be seen in Table 24.

Table 24: The Inferred Prioritization of Loads based on Load Dependencies

\begin{tabular}{|l|l|l|l|l|}
\hline Priority & $\begin{array}{c}\text { Load } \\
\text { Off }\end{array}$ & $\begin{array}{c}\text { Affected } \\
\text { Loads }\end{array}$ & $\begin{array}{c}\text { Number of } \\
\text { Affected Cells }\end{array}$ & Affected Cells \\
\hline 1 & F & F, B, C & 6 & R6, R2, R3, Hospital, Health Centre 2, Pump 2 \\
\hline
\end{tabular}




\begin{tabular}{|l|l|l|l|l|}
\hline 2 & E & E, A & 4 & R5, R1, Health Centre 1, Pump 1 \\
\hline 3 & G & G, D & 3 & R7, R 4, Pump 3 \\
\hline 3 & C & C & 2 & R3, Hospital \\
\hline 4 & D & D & 1 & R4 \\
\hline 5 & B & B & 2 & R2, Health Centre 2 \\
\hline 5 & A & A & 2 & R1, Health Centre 1 \\
\hline
\end{tabular}

\subsection{Water Production Policies}

\subsubsection{Truck Borne Supply (TBS) Inclusion}

The effect of TBS being used on the system was also investigated. Based on multiple factors such as truck capacity, time, human resources and other efficiency related issues, TBS was clearly not an alternative to the pumped water distribution system. Considering this, a more practical use of the TBS was to supply sufficient water resources to medical facilities and residences. This resulted in an improvement of the operation of the medical facilities as well as a small reduction in the number of sickly being generated by the residences. There was an even greater need for TBS in the two pump damaged test scenario. This shows that with the TBS/MOP Schemes operating at full efficiency, not only will there be a reduction in the number of sickly generated from residences, but there will also be a minimum level of sickly needing treatment at medical cells.

\subsection{Further Discussion/Future Work}

The method of energy distribution used worked effectively but did not consider scalability of the model as well as the number of loads for any given model. Further analysis of an energy distribution scheme which takes scalability into account should be developed since the model simulated was relatively small. The addition or removal of elements will not only entail making changes to the heuristic controllers for water and energy distribution but also the controller which facilitates the simulation and analysis of all possible unique combinations of the system.

\section{Conclusion}

In this study, a simulation and control framework was developed for evaluating response decisions for natural disaster scenarios aiming at reducing the life loss count. The framework targets water and electricity utilities and produces recommendations for the best possible policy decision to reduce the casualty count for each disaster scenario. For disasters affecting electricity, a heuristic controller was able to find the best load combinations which should be rotated based on the scenario. As for the water testing, the heuristic controller can generate the anticipated number of deaths for each possible simulated combination as well as take preventative measure to reduce the number of deaths in a given scenario. The framework has put forward a testing approach which aims at looking at all possible situations which can exist, be it for one critical infrastructure being damaged at a point in time or when both critical infrastructures has been damaged simultaneously.

\section{References}

[1] H. Ahmadi, A. Alsubaie, and J. R. Mart'1. Distribution system restoration considering critical infrastructures interdependencies. In 2014 IEEE PES General Meeting — Conference Exposition, pages 15, July 2014. 
[2] A. Alsubaie, K. Alutaibi, and J. Marti. Resources allocation in emergency response using an interdependencies simulation environment. In 2015 IEEE Canada International Humanitarian Technology Conference (IHTC2015), pages 1-4, May 2015.

[3] A. Alsubaie, J. Marti, K. Alutaibi, A. Di Pietro, and A. Tofani. Resources allocation in disaster response using ordinal optimization based approach. In 2014 IEEE Canada International Humanitarian Technology Conference - (IHTC), pages 1-5, June 2014.

[4] Zubair Ahmed. Disaster risks and disaster management policies and practices in Pakistan: A critical analysis of disaster management act 2010 of Pakistan. International Journal of Disaster Risk Reduction, 4:15-20, 2013.

[5] A. Shypanski, V. H. Pham, A. Cunha, and E. Yanful. Interdependent infrastructure modelling: Integration of domestic water models. In 2011 24th Canadian Conference on Electrical and Computer Engineering (CCECE), pages 001495-001498, May 2011.

[6] M. Khouj, C. Lopez, S. Sarkaria, and J. Marti. Disaster management in real time simulation using machine learning. In 2011 24th Canadian Conference on Electrical and Computer Engineering (CCECE), pages 001507-001510, May 2011.

[7] Liangzhi Li, Kaoru Ota, Mianxiong Dong, and Wuyunzhaola Borjigin. Eyes in the dark: Distributed scene understanding for disaster management. IEEE Transactions on Parallel and Distributed Systems, 2017.

[8] Sowedi Masaba, David N Mungai, Moses Isabirye, and Haroonah Nsubuga. Implementation of landslide disaster risk reduction policy in Uganda. International Journal of Disaster Risk Reduction, 2017.

[9] Julia Crowley. A measurement of the effectiveness and efficiency of pre-disaster debris management plans. Waste Management, 62:262-273, 2017.

[10] Asjad Naqvi. Deep impact: Geo-simulations as a policy toolkit for natural disasters. World Development, 2017.

[11] S Durga and R Swetha. Disaster prevention and control management. Procedia Earth and Planetary Science, 11:516-523, 2015.

[12] Rahman, Hafiz Abdur, Mazana Armstrong, DeTao Mao, and Jose R. Marti. "I2Sim: a matrix-partition based framework for critical infrastructure interdependencies simulation." In 2008 IEEE Canada Electric Power Conference, pp. 1-8. IEEE, 2008.

[13] J. S. Kumar, M. A. Zaveri, and M. Choksi, "Task based resource schedul-ing in iot environment for disaster management," Procedia computerscience, vol. 115, pp. 846-852, 2017.

[14] M. Choksi and M. A. Zaveri, "Multiobjective based resource allocationand scheduling for postdisaster management using iot," Wireless Commu-nications and Mobile Computing, vol. 2019, 2019.

[15] S. Basu, S. Roy, S. Bandyopadhyay, and S. D. Bit, "A utility drivenpost disaster emergency resource allocation system using dtn," IEEETransactions on Systems, Man, and Cybernetics: Systems, 2018.

[16] M. Muaafa, A. L. Concho, and J. Ramirez-Marquez, "Emergency resourceallocation for disaster response: An evolutionary approach,” Available atSSRN 2848892, 2014. 